\title{
Results on thermal annealing of Graphite Enhanced polystyrene insulations
}

\author{
Ákos Lakatos ${ }^{1, a)}$ and Sándor Szanyi ${ }^{1}$ \\ ${ }^{1}$ University of Debrecen, Faculty of Engineering, Department of Building Services and Buildings and \\ Engineering, Hungary, 4028, Debrecen, Otemetö str 2-4. \\ ${ }^{a)}$ Corresponding author: alakatos@eng.unideb.hu
}

\begin{abstract}
From the beginning, the buildings have been tasked with protecting man from the external environmental impacts. Technological development has brought with its buildings and building structures development. Nowadays, the expectation is that in the interior of buildings it is for man to ensure a comfortable environment at all times of the year. External environmental conditions offsetting specifically requires a large amount of energy. In the European Union for buildings, its energy consumption accounts for about $20-40 \%$ of total energy consumption. The amount of energy required can be reduced, for which is a good solution. With thermal insulation, we reduce both in the building the transfer of the amount of heat generated or introduced into the building to the external environment, or it also minimizes the amount of heat that enters by radiation. Polystyrene insulations are ordinary, and their thermal properties are well known. However, the most promising type is the graphite enhanced one with relatively little information. These graphite doped material products have much better thermal insulation properties than the conventional (white) ones. In this paper, measurements of thermal conductivity after thermal annealing will be presented. Moreover, we will show some structural changes, and differential scanning calorimetry measurement results, too.
\end{abstract}

\section{INTRODUCTION}

The concept of thermal insulation is not a new thing at all. As technology advances, insulation materials had to come in different and different ways to be appropriate. Over time, condensation and vibration damping came to the fore. Thermal insulation materials can have a closed or open cell structure. Closed-cell structure, in this case, the entire insulation material consists of completely closed cells. The cells are compressed, so air and moisture cannot enter the insulation material and are more stable and stiff material structures like an open cell. In contrast, an open-cell is open by definition consists of cells, which makes the material more flexible and softer. [1]

Expanded polystyrene (EPS) is mainly reached by evaporating the pentane to gas-phase added into the polystyrene balls. Through this process white, rigid, and open or closed-cell foam will be formed [2]. To further reduce the thermal conductivity of the polystyrene insulation materials, graphite nanotubes or carbon particles can be added to the polystyrene grains during the manufacturing procedure. Graphite enhanced polystyrene type insulation sample is one of the most promising materials for reducing thermal energy loss of buildings. Due to their nano-structure. Lakatos found that by adding different types of graphite particles (surface-modified nanographite particulates, carbon nanotubes, disperse graphene fillers, or graphene oxide) to the polystyrene grains during the manufacturing process, the thermal conductivity of the composite can be lower significantly [3-6]. Graphite has very good infrared radiation absorbing capability and it has a beam scattering behavior, too. During a heat transfer process, multiple heat transfer modes occur simultaneously. By the low-density thermal insulator, convection is also present in the gases in the cells, the thermal conduction through a material matrix, and heat radiation between solid parts of the material. [7] Thermal conductivity and convection are linearly proportional to the temperature difference, however, heat radiation goes exponentially. However, during the manufacturing process, we can add carbon nanotubes, which can significantly reduce the heat radiation heat transfer as they reflect and absorb heat. In this respect, even more, effective the addition of expanded graphite, which is the most stable form of carbon, in addition to graphite, proved to be it is also much easier to process. [8-10] 


\section{Thermal aging of materials}

The aging of materials is a process in which their physical, mechanical, and thermal properties change over time. Aging in the material can be artificially induced by irradiation (UV or infrared) or heat treatments. Heat treatment of materials can also increase the kinetic processes that take place in them, as well as the speed of chemical and physical degradation processes within the materials. The fact is, however, that heat treatments at elevated temperatures do not take place under typical climatic conditions. In the case of thermal insulation materials, artificial aging is usually carried out by heat treatment at $70^{\circ} \mathrm{C}$ for a longer period. The durability of the thermal conductivity is important in the design, both from an operational and economic point of view. Aging at higher temperatures $\left(\sim 200^{\circ} \mathrm{C}\right)$ is important for materials that can also be used to insulate pipes transporting hot media (industrial, power plant, chimney) (eg. fibrous aerogel, rock wool). Aging depends on the type, morphology, structure, foaming agents, temperature, and thickness of the material. Building materials must have high durability as they last a lifetime they must have adequate functional properties. Nevertheless, it often happens that after a short time they do not meet the various requirements, so it is their service life is greatly shortened. Besides, a single layer in a building structure damage can endanger the entire structure. More expensive maintenance and building materials possible replacement will further increase costs. To avoid these problems, such building materials that are documented to be suitable in the long run should be used properties. $[11,12]$ These are substances that have a long-term effect they are resistant to external natural conditions, or even after proper artificial aging their properties deteriorate. Regarding thermal insulation materials

\section{MEASUREMENTS AND METHOD}

The measurements were executed in the Building Physics Laboratory of the University of Debrecen Faculty of Engineering. The measurement details are written in the latest paper of the author. The thermal annealing of the samples was executed in Venticell 111 drying equipment. The thermal conductivity measurements were executed in Holometrix lambda 2000 equipment. The measurement orders can be found in our recent papers. $[2,3,7,8]$ Graphite enhanced polystyrene materials with $30 \times 30 \mathrm{~cm}$ base area and with $5 \mathrm{~cm}$ thickness were tested. Differential scanning calorimetry measurements were executed also with Netzsch Sirius 3500 DSC equipment. The measurement was executed in Nitrogen gas, between 0 to $170{ }^{\circ} \mathrm{C}$ degree with $10 \mathrm{~K} / \mathrm{min}$ heating.

\section{RESULTS}

\section{Durability}

One of the most common issues with thermal insulation materials is that in the long run as well whether they can maintain the same thermal conductivity value. In this case, the graphite is expanded when testing polystyrene, the deterioration of its thermal conductivity may occur because during its lifetime, the composition of the gases in the cells may change, diffusing into the cells air has a much higher thermal conductivity than the original gases there. One to determine the thermal conductivity of any aged insulating material experimental and modeling methods, which require a new copy of the insulation material and its thermal conductivity. The experimental methods use artificial aging, they accelerate the diffusion of gases into the material. With artificially accelerated aging, the material changes in its properties during aging can be examined relatively quickly. [26] One way to do this is to keep the insulating material at a higher temperature than that operating temperature, which I also used. Another possible experimental solution is a material cutting into thin slices, in this case also the aging process will be much faster. If the material is kept at a higher temperature for a while than the temperature it has building structure on average exposed, it is artificially aged (thermal aging). How long a certain time interval corresponds to a higher temperature compared to normal conditions of use, with a so-called Arrhenius relation can be determined. The Arrhenius equation in the present case describes the reaction rate as a function of temperature, as they take place faster at higher temperatures reactions involving a thermally insulating material, such as the diffusion of air into the pores. The by writing a relation, knowing the temperatures and durations I examined, and we can determine how much the time interval spent in the drying chamber corresponds to normal

conditions.

The Arrhenius relation:

$$
t_{a}=\frac{t_{s}}{2^{\left(T_{a}-T_{s}\right) / 10}}
$$


where

$-t_{\mathrm{a}}$ : aging time at a given temperature,

$-t_{\mathrm{s}}$ : service time at the tested temperature,

$-T_{\mathrm{a}}$ : aging temperature $\left(70^{\circ} \mathrm{C}\right)$

$-T_{\mathrm{s}}$ : service temperature $\left(10^{\circ} \mathrm{C}\right)$

\section{Thermal conductivity measurement results}

Firstly, graphite enhanced samples were heat-treated at $70{ }^{\circ} \mathrm{C}$ from 1 to 50 days, while on some days the drying was interrupted and the thermal conductivity of the sample was measured. Fig. 1 presents the calculated service time at $70^{\circ} \mathrm{C}$. As a result of the calculation 9 years were reached for the service time.

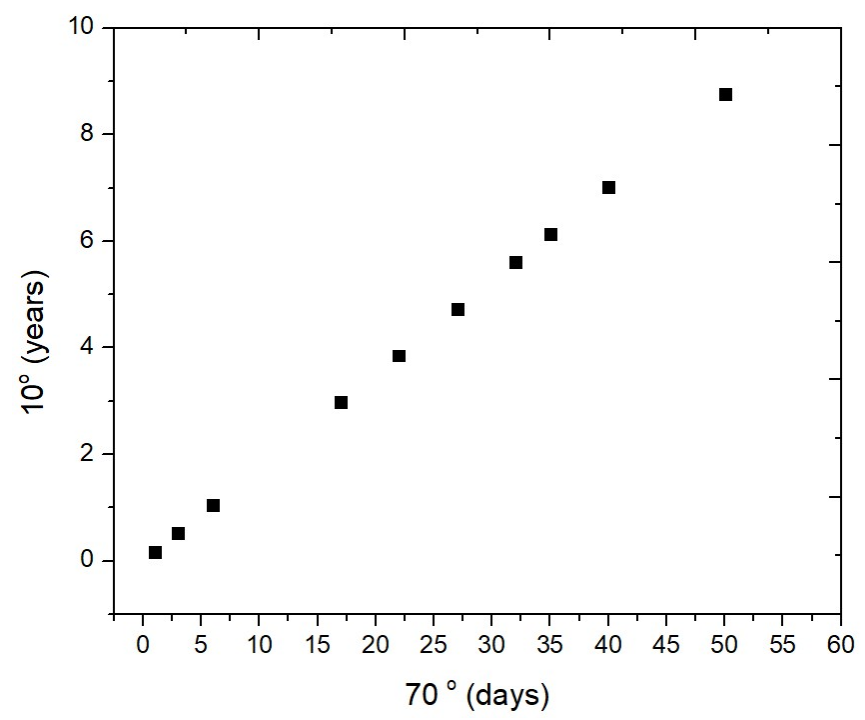

FIGURE 1. The calculated service time by the Arrhenius law

In Fig. 2. one can see the thermal conductivity measurement results. It is observable, that the measured thermal conductivities are around $0.0367 \mathrm{~W} / \mathrm{mK}$, which does not change after the thermal annealing. 


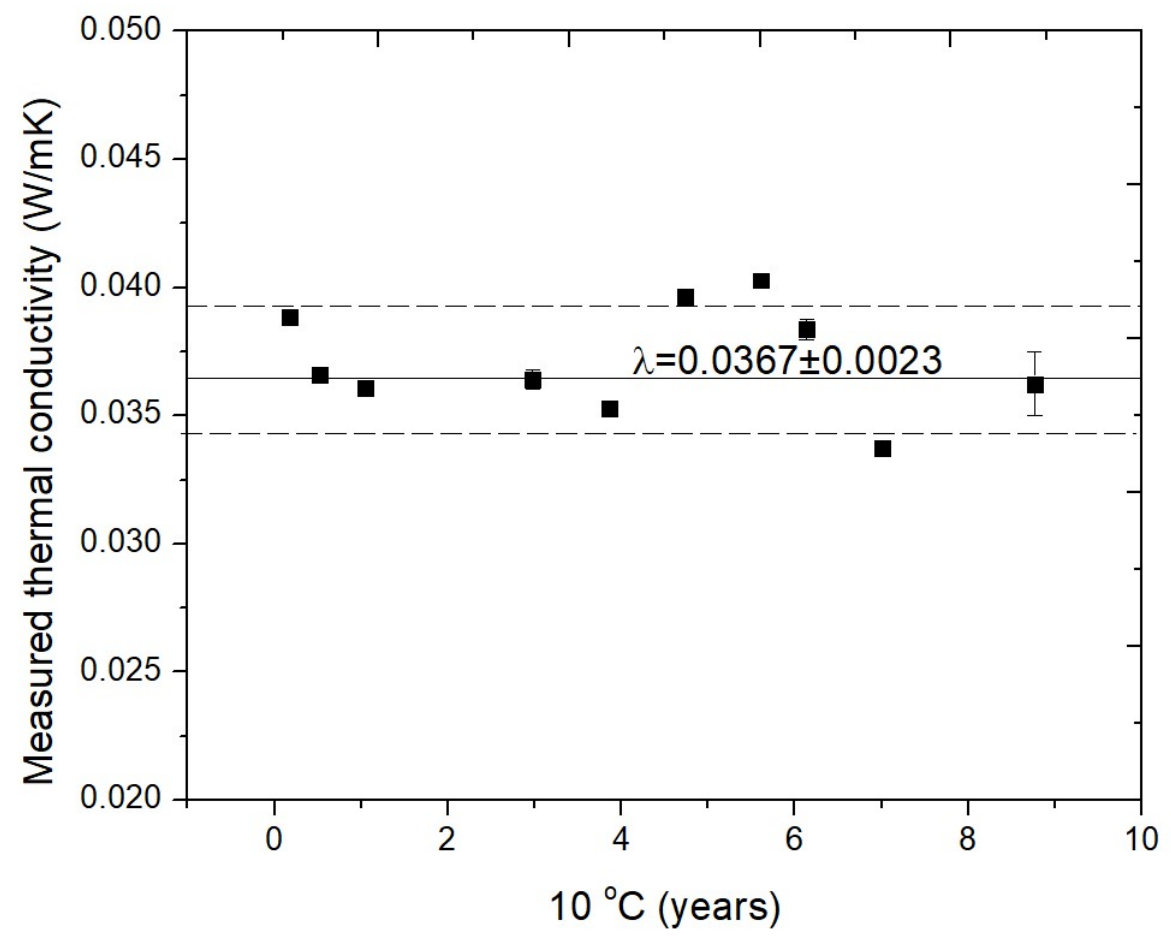

FIGURE 2. The measured thermal conductivities

\section{Thermal annealing at higher temperatures}

To examine what maximum aging rate can be used, so what could be the maximum drying temperature, 3 different samples were dried differently. At first, a sample was kept at $110{ }^{\circ} \mathrm{C}$ for 1 day in a drying oven. This sample had $30 \mathrm{~cm} \times 30 \mathrm{~cm}$ base are and it has shrinkage to $12 \mathrm{~cm} \times 12 \mathrm{~cm}$, its thickness also decreased with a similar proportion, from 3.5 to 1.4 centimetres (see Fig. 3a). Its density was $16.80 \mathrm{~kg} / \mathrm{m}^{3}$ initially and raised to $278.43 \mathrm{~kg} / \mathrm{m}^{3}$. After this, a new sample was kept in the drying chamber at $110^{\circ} \mathrm{C}$, but only for 1 hour (see Fig. $3 \mathrm{~b}$ ). This specimen also became unusable, its pore structure completely changed. Its size has been reduced to $21 \mathrm{~cm} x$ $21 \mathrm{~cm} \times 2.6 \mathrm{~cm}$, its density became $50.91 \mathrm{~kg} / \mathrm{m}^{3}$. We have kept the third specimen at $100^{\circ} \mathrm{C}$ for 1 -hour time interval in the dryer, and we reached that it has not suffered such a great deformation as the other two, but still, significant deformation occurred. The regular square shape distorted, each side has a different length, $24.8 \mathrm{~cm} \mathrm{x} 26.3 \mathrm{~cm}$ (see Fig.3c. Its density raised to $25.89 \mathrm{~kg} / \mathrm{m}^{3}$. We have to mention that due to the shrinkage we could not measure the thermal conductivity of these samples.
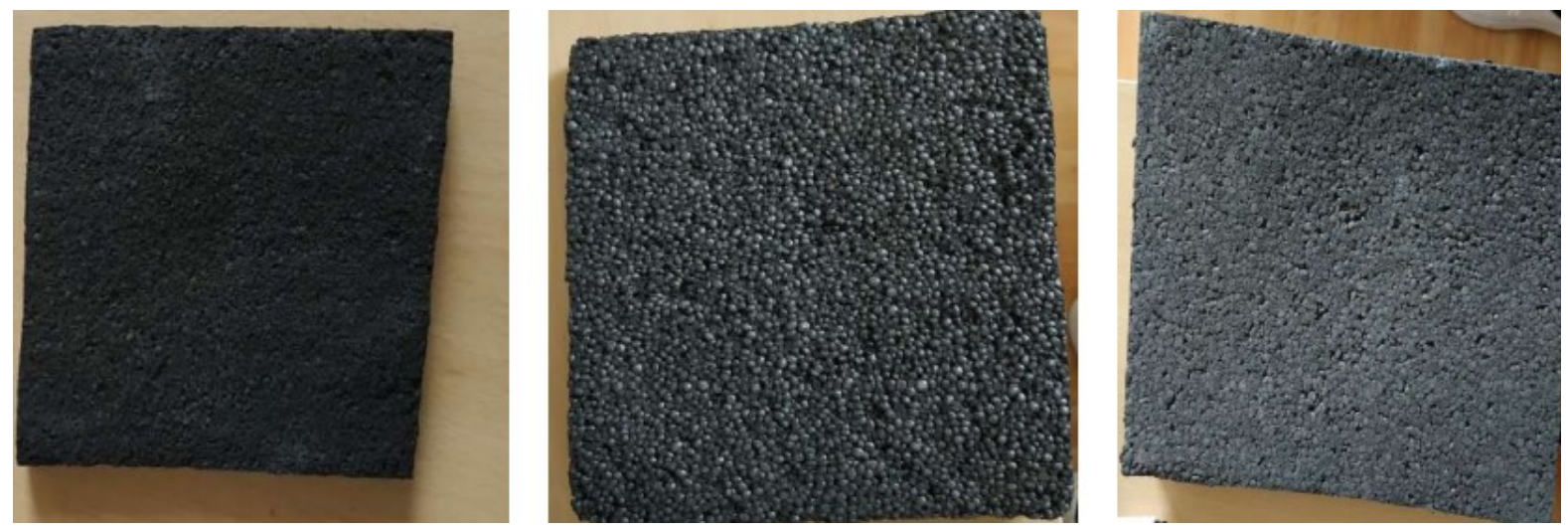

FIGURE 3. A, B, C. The annealed samples 
From the left to the right one can see the photo of the annealed samples at $110^{\circ} \mathrm{C}$ for 1 day, and for 1 hour, and at $100{ }^{\circ} \mathrm{C}$ for 1 hour, respectively.

\section{Differential scanning calorimetry measurement results}

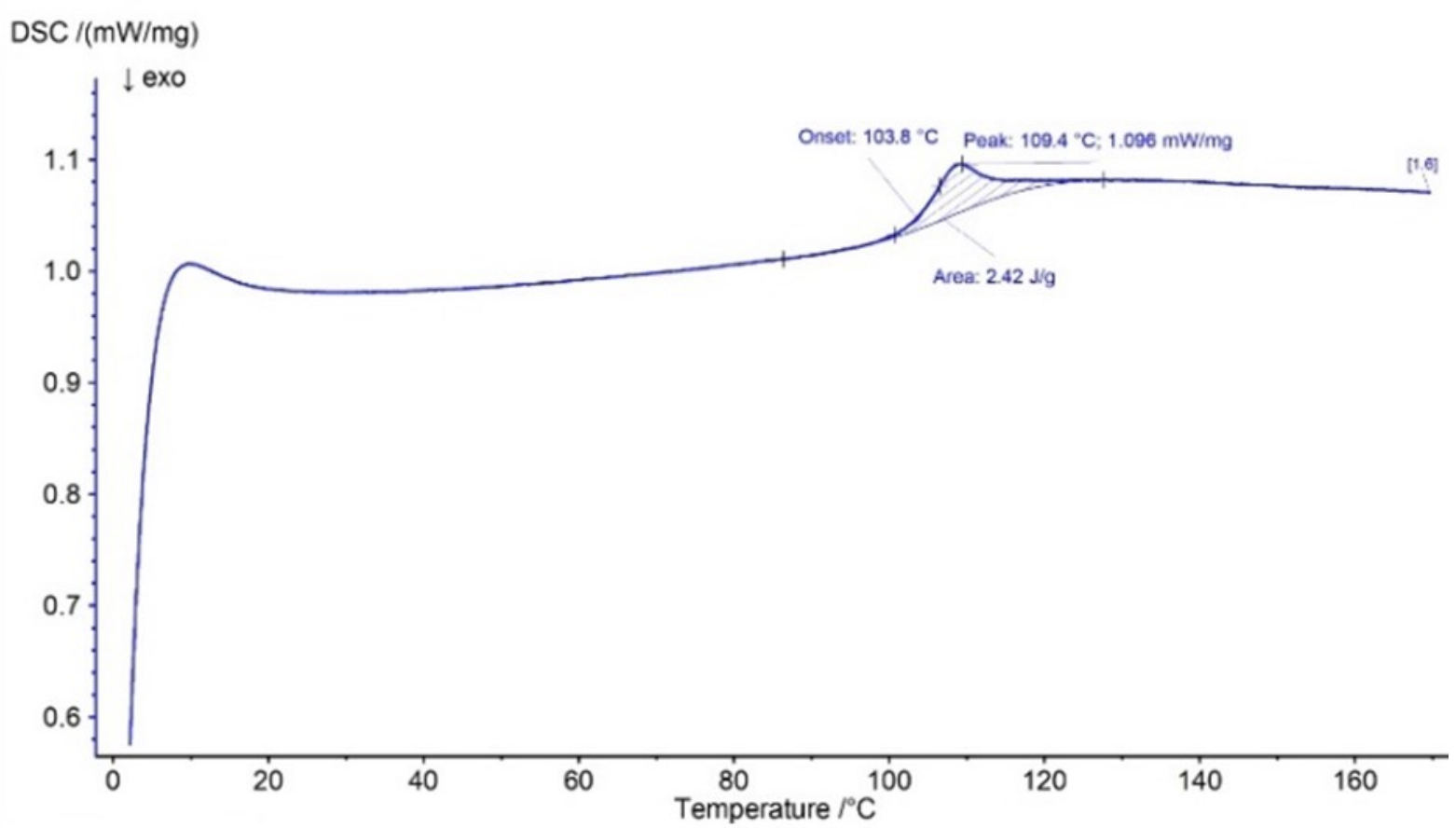

FIGURE 4. DSC curve of the graphite enhanced sample

Differential scanning calorimetry curve can be found in Fig.4. One can see the increasing sign between 20 and $100{ }^{\circ} \mathrm{C}$, while a peak is observable at about $110^{\circ} \mathrm{C}$. This result has a good correlation with the thermal conductivity measurement and with the annealing results, while the sample is stable till about $90^{\circ} \mathrm{C}$ over this structural changes occur.

\section{CONCLUSIONS}

These days the correct use of insulation materials is more important than ever. There are many different types of insulation materials. But, the determination of the properties of the insulator materials, as well as the variation of them due to the various external effects, is so important. In this study, we showed the benefits of graphite expanded polystyrene. We have shown the application possibilities of this material. As it turned out, graphite expanded polystyrene has more favorable thermal insulation properties than the most artificial and natural thermal insulation materials, thanks to its graphite particle contaminants. I found that under normal conditions, the graphite enhanced sample does not deteriorate even in 9 years as thermal insulation. I found the maximum temperature at which graphite expanded can be heat treated is about $90-100{ }^{\circ} \mathrm{C}$. At $70^{\circ} \mathrm{C}$, it does not suffer any damage over a long time. So its maximum heat treatment temperature can be set to about $90^{\circ} \mathrm{C}$, which is the maximum for artificial aging also assigns its speed to this temperature. Differential scanning calorimetry results in a further state of the above-mentioned results.

\section{ACKNOWLEDGMENTS}

The work was partially financed by the EFOP 3.6.1-16-2016-00022 project, Venture Catapult Program of the University of Debrecen and it is co-financed by the European Union and the European Social Fund. The theory 
and the calorimetric (DSC) measurements were executed by Ákos Lakatos and this was supported by János Bolyai Research Scholarship of the Hungarian Academy of Sciences, grant number: Ákos Lakatos - BO/269/20.

\section{REFERENCES}

1. U. Berardi and M. Naldi, En. Build. 144, 262-275 (2017).

2. Á. Lakatos, J. Therm. Anal. Calorim. 133,1 329-335 (2018).

3. Á. Lakatos, I Deák, U. Berardi, Int. Rev. Appl. Sci. Eng. 9,2 163-168 (2018).

4. A. Nowoświat, P. Krause, A. Miros, J. Build. Eng. 34, 101920 (2021).

5. R. Coquard and D. Baillis, J. Heat, Tran. 128, 538-549 (2006).

6. H. S. Park, B. K. Oh, T. Cho, Compos. B Eng. 93, 252-264 (2016).

7. Á. Lakatos and F. Kalmár, Mater. Struct. 46, 1101-1105 (2013).

8. Z. Kovács, S. Szanyi, I. Budai, Á. Lakatos, Smart Innov. Syst. Techn. 163, 73-82 (2020).

9. M. Koru, Arab. J. Sci. Eng. 41, 4337-4346 (2016)

10. M. P. Tran, P. Gong, C. Detrembleur, J. M. Thomassin, P. Buahom, M. Saniei, S. Kenig, C. B. Parka, S. E. Lee, SPE ANTE, 1870-1882 (2016).

11. A. Miros, Thermal aging effect on thermal conductivity properties of mineral wool pipe samples at high temperature, in: "Proceedings of the 3 Rome, Italy-June 8-10", Paper No. HTFF 172 (ISSN: 2369-8136) (2017).

12. B. P. Jelle, J. Mater. Sci. 47 6475-6496 (2012). 